\title{
PAPAN SEMEN-GYPSUM DARI CORE-KENAF (Hibiscus cannabinus L.) MENGGUNAKAN TEKNOLOGI PENGERASAN AUTOCLAVE
}

\author{
Cement-Gypsum Board from Core-Kenaf (Hibiscus cannabinus L.) Using Curing AutoclaveTechnology \\ Rohny Setiawan Maail, Dede Hermawan,Yusuf Sudo Hadi
}

\begin{abstract}
Cement and gypsum bonded cellulosic fiber reinforced materials are ultimately ideal ecological building products. Their capability to use industrial coproducts and wastes as both their matrix material make its reinforcement also environmentally sustainable products. The objective of this study was to evaluate the effect of proportion cement-gypsum and curing autoclave time on the properties of cement gypsum board from core-kenaf. Three levels of proportion cement and gypsum were applied, namely; 40:60, 50:50, and 60:40, where cements contain at face-back layers and gypsum contain at core layers. Five levels of curing autoclave time were applied, namely ; conventional curing 2 weeks (control), curing autoclave 2 , 4,8 , and 16 hours. $\mathrm{CaCl}_{2} 3 \%$ and Borax $2 \%$ was used as an accelerator and retarder. The physical and mechanical properties of cement-gypsum board were observed in according to JIS A 5417-1992. The results show that the physical and mechanical properties were gain on proportion of cement-gypsum 60:40 with 8 hours curing autoclave.
\end{abstract}

Key words : Core-kenaf, Cement-gypsum board, Autoclave

\section{PENDAHULUAN}

Kenaf (Hibiscus cannabinus L.) sebagai salah satu tanaman penghasil serat memiliki potensi yang dapat dikembangkan sebagai bahan baku produk pengganti kayu bulat. Tanaman yang termasuk dalam famili Malvaceae ini merupakan tanaman yang cepat tumbuh, biasanya dipanen pada umur 125 - 140 hari (Dempsey 1975). Dengan diameter $35 \mathrm{~mm}$, kenaf dapat menghasilkan serat sekitar 4,4 ton/ha. Setelah diambil seratnya, tanaman ini menghasilkan hasil ikutan (By Product) berupa core atau inti kenaf. Dalam satu hektar dapat dihasilkan core-kenaf kering udara (kadar air 15\%) 6 - 8 ton (Sastrosupadi 1984). Ini merupakan hasil ikutan yang berpotensi untuk dimanfaatkan sebagai bahan baku papan semengypsum. Melihat kepada perkembangan papan semen hingga saat ini, disamping memiliki kelebihan stabilitas dimensi yang tinggi, namun memiliki masalah dimana waktu pengerasan semen (curing) yang relatif lama yaitu minimal 28 hari ( \pm 1 bulan) dan merupakan jenis panel yang cukup berat. Dibandingkan dengan papan gypsum, papan gypsum memiliki kelebihan dimana merupakan panel yang ringan dan mudah dalam pengerjaan. Namun kelemahan utama dari papan gypsum adalah mudah menyerap air serta mempunyai kekuatan yang rendah. Salah satu cara untuk mengatasi semua permasalahan dari papan semen dan papan gypsum tersebut di atas adalah dengan membuat papan semen-gypsum (subtitusi semen dengan gypsum pada beberapa proporsi tertentu) dengan perlakuan pengerasan (curing) autoclave.

Penelitian ini bertujuan untuk mengetahui pengaruh proporsi semen-gypsum dan waktu curing autoclave terhadap sifat fisis dan mekanis papan semen-gypsum dari core-kenaf dan menentukan jenis proporsi semen-gypsum serta waktu curing autoclave terbaik dalam pembuatan papan semen-gypsum dari core-kenaf serta keunggulannya dibanding proses pembuatan papan semen-gypsum dengan curing konvensional selama 2 minggu.

\section{BAHAN DAN METODE}

\section{Persiapan Bahan dan Pengukuran Suhu Hidrasi}

Penelitian ini dilakukan dengan bahanbahan antara lain partikel dari core-kenaf (Hibiscus cannabinus L.) berumur 4 bulan, berbentuk slivers dengan ukuran partikel antara 2 - $3 \mathrm{~mm}$ yang diperoleh dari PT. Abadi Barindo Autotech (PT. ABA), serta perekat berupa semen Portland dan gypsum. Sebelum proses 
pembuatan papan, terlebih dahulu dilakukan pengukuran suhu hidrasi untuk melihat kesesuaian core-kenaf sebagai bahan baku papan semen-gypsum dan hasil pengukuran dikelompokkan dalam standar pengukuran suhu hidrasi berdasarkan standar LPHH Dephut (Kamil 1970).

\section{Pembuatan Papan}

Papan semen-gypsum dibuat dengan ukuran $30 \mathrm{~cm} \times 30 \mathrm{~cm} \times 1,2 \mathrm{~cm}$ dengan sasaran kerapatan $1,2 \mathrm{~g} / \mathrm{cm}^{3}$. Papan semen-gypsum yang dibuat dari semen, gypsum dan partikel corekenaf ini dibentuk dengan formulasi untuk lapisan face dan back papan dari campuran semen, partikel core-kenaf dan air dengan perbandingan 2,5:1:1,25 (Hermawan 2001). Sedangkan untuk lapisan tengah papan dibuat dari campuran gypsum, partikel core-kenaf dan air dengan perbandingan 3:1:1,5 (Febrianto 1986). Bahan tambahan yang digunakan antara lain accelerator $\mathrm{CaCl}_{2}(3 \%)$ dan retarder boraks (2\%).

\section{Pengujian Papan}

Pengujian sifat fisis dan mekanis papan semen-gypsum dilakukan berdasarkan Japanesse Industrial Standard JIS A 5417-1992 meliputi pengujian kerapatan, kadar air, daya serap air, pengembangan tebal dan linier, keteguhan rekat (IB), modulus eleastisitas (MOE), keteguhan patah (MOR) dan kuat pegang sekrup. Nilai yang dibandingkan adalah nilai rata-rata setiap perlakuan dengan kombinasinya dari masing-masing sifat yang diuji. Hasil pengujian diolah dengan menggunakan model Regresi Linier Berganda dengan dua peubah bebas yakni : 1) proporsi perbandingan semen-gypsum (berdasarkan berat) terdiri atas tiga taraf, yaitu 40:60, 50:50 dan 60:40; dan 2) waktu curing autoclave terdiri atas lima taraf, yaitu : curing konvensional (2 minggu), curing autoclave 2, 4, 8 dan 16 jam. Penelitian dilakukan dengan tiga ulangan sehingga terdapat 45 contoh uji.

\section{HASIL DAN PEMBAHASAN}

\section{Suhu Hidrasi}

Gambar 1 menunjukkan bahwa campuran gypsum dan air memiliki suhu hidrasi tertinggi yaitu $52^{\circ} \mathrm{C}$ dengan pencapaian suhu maksimum terjadi dalam waktu 20 menit, diikuti campuran gypsum, air dan serbuk kenaf dengan suhu hidrasi $50^{\circ} \mathrm{C}$; kemudian campuran gypsum, air, serbuk kenaf dan retarder boraks ( $2 \%$ dan $5 \%$ ) sebesar $48^{\circ} \mathrm{C}$ dengan waktu pencapaian suhu maksimum yang hampir sama (36 dan 38 menit). Waktu ini tergolong singkat dibandingkan dengan waktu hidrasi semen.

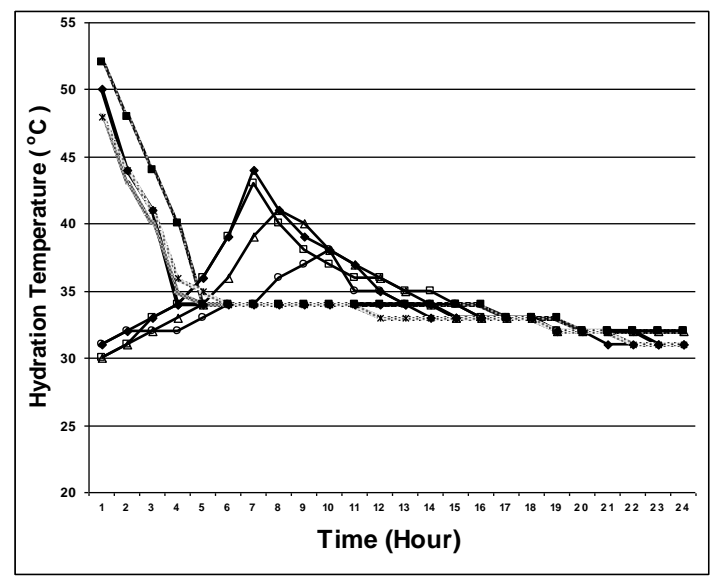

Legend:

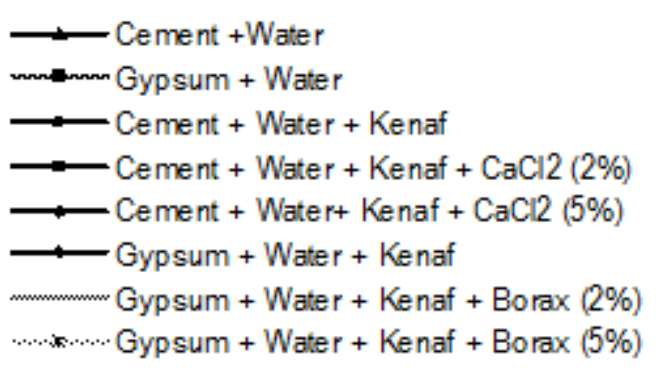

Figure 1. Grafic of hydration temperature

Berbeda dengan gypsum yang mempunyai sifat cepat mengeras bila dicampur air, campuran semen dan air memiliki suhu maksimum $41{ }^{\circ} \mathrm{C}$ dan dicapai dalam waktu 8 jam, sedangkan campuran semen, air dan serbuk kenaf memiliki suhu maksimum $38^{\circ} \mathrm{C}$ dicapai dalam waktu 10 jam. Jika ditambahkan accelerator $\mathrm{CaCl}_{2}$ sebesar $2 \%$ dan $5 \%$ ke dalam campuran semen, air dan serbuk kenaf maka suhu maksimum yang terbentuk adalah $43^{\circ} \mathrm{C}$ dan $44^{\circ} \mathrm{C}$ dalam waktu 7 jam. Bila disesuaikan dengan pengelompokan suhu hidrasi semen oleh LPHH Dephut dalam Kamil (1970) maka semua perlakuan yang diterapkan dalam penelitian ini menunjukkan hasil yang tergolong 'baik' karena suhu maksimum lebih besar dari $41^{\circ} \mathrm{C}$. Hal ini memberikan indikasi bahwa kenaf (Hibiscus cannabinus L.) dapat digunakan atau sesuai sebagai bahan baku pembuatan papan semen-gypsum. 


\section{Kerapatan}

Nilai kerapatan papan berkisar dari 1,05 - 1,14 $\mathrm{g} / \mathrm{cm}^{3}$. Kerapatan tertinggi yaitu $1,14 \mathrm{~g} / \mathrm{cm}^{3}$ diperoleh pada papan dengan proporsi semen 60 dan gypsum 40 dengan curing autoclave 8 jam, sedangkan nilai kerapatan terendah yaitu 1,05 $\mathrm{gr} / \mathrm{cm}^{3}$ diperoleh pada papan dengan proporsi semen 40 dan gypsum 60 dengan curing konvensional selama 2 minggu. Histogram kerapatan papan selengkapnya dapat dilihat pada Gambar 2.

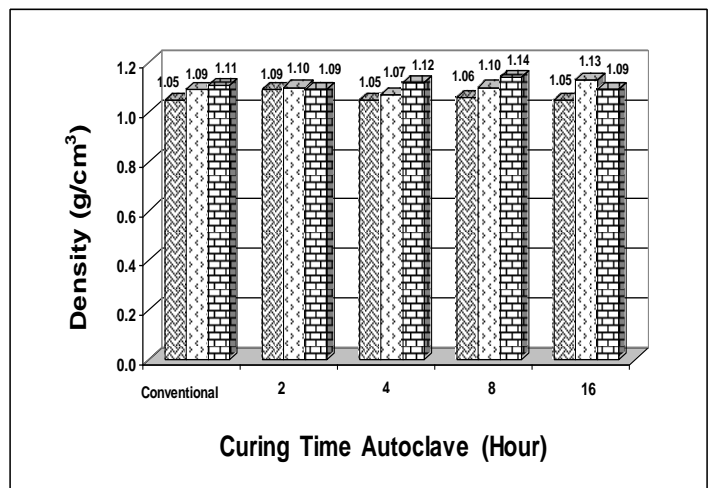

Legend :

图 : Proportion of Cement 40 : Gypsum 60

$\square$ : Proportion of Cement 50 : Gypsum 50

표 : Proportion of Cement 60 : Gypsum 40

Figure 2. Histogram of board density

Hasil analisis ragam menunjukkan bahwa kerapatan papan dipengaruhi oleh proporsi semen-gypsum tanpa dipengaruhi oleh waktu curing autoclave dan penggunaan proporsi semen yang lebih besar dari proporsi gypsum yaitu proporsi semen 60 dan gypsum 40 akan mempengaruhi kerapatan papan dimana kerapatan papan menjadi semakin tinggi dan mendekati kerapatan sasaran.

\section{Kadar Air}

Hasil pengukuran kadar air papan berkisar antara 5,74 - 8,14\%. Gambar 3 menunjukkan bahwa papan dengan proporsi semen 40 dan gypsum 60 dengan curing autoclave 4 jam memiliki kadar air tertinggi (8,14\%), sedangkan nilai kadar air terendah didapat pada papan dengan proporsi semen 60 dan gypsum 40 dengan curing autoclave 2 jam (5,74\%). Hasil analisis ragam menunjukkan bahwa nilai kadar air papan semen-gypsum tidak dipengaruhi oleh proporsi semen-gypsum maupun waktu curing autoclave yang digunakan dalam proses pembuatan papan dan berdasarkan JIS A 54171992 yang mensyaratkan kadar air papan maksimal $16 \%$ maka nilai kadar air papan semen-gypsum yang dihasilkan seluruhnya memenuhi standar tersebut.

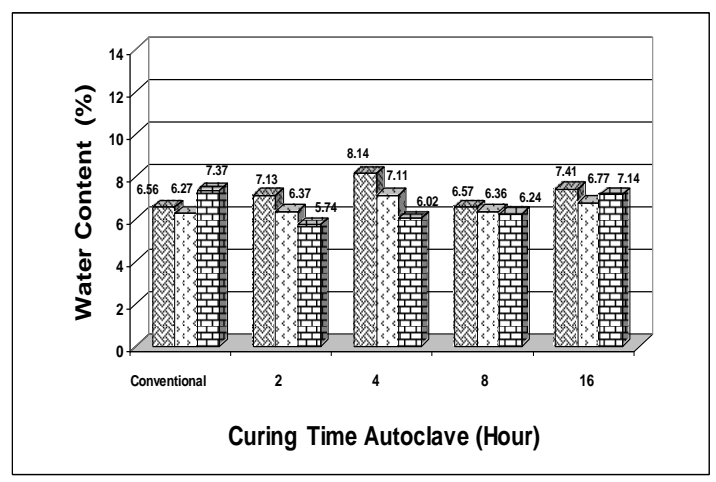

Legend : See Figure 2

Figure 3. Histogram of board water content

\section{Daya Serap Air}

Nilai daya serap air papan semen-gypsum seperti disajikan pada Gambar 4 menunjukkan bahwa setelah perendaman selama 2 jam berkisar antara 15,57 - 25,27\%, sementara daya serap air papan setelah perendaman selama 24 jam berkisar antara $21,70-34,39 \%$. Nilai tertinggi setelah perendaman 2 jam didapat pada papan dengan proporsi semen 40 dan gypsum 60 dengan curing konvensional selama 2 minggu $(25,27 \%)$, sedangkan nilai terendah didapat pada papan dengan proporsi semen 60 dan gypsum 40 dengan curing autoclave 8 jam $(14,14 \%)$. Setelah perendaman 24 jam, nilai daya serap air tertinggi didapat pada papan dengan proporsi semen 40 dan gypsum 60 dengan curing konvensional selama 2 minggu $(34,39 \%)$ dan nilai terendah didapat pada papan dengan proporsi semen 60 dan gypsum 40 dengan curing autoclave 8 jam $(21,70 \%)$.

Hasil analisis ragam menunjukkan bahwa nilai daya serap air papan dipengaruhi oleh proporsi semen-gypsum yang digunakan, baik setelah perendaman 2 jam maupun 24 jam; dimana proporsi gypsum yang semakin besar terhadap semen akan menyebabkan daya serap air papan setelah perendaman 2 jam dan 24 jam menjadi semakin tinggi. Nilai daya serap air papan semen-gypsum yang tinggi oleh papan yang memiliki proporsi gypsum lebih besar dari 
semen disebabkan karena kandungan gypsum dengan sifat absorben air yang lebih besar, sehingga memberi peluang menyerap air lebih banyak. Sebagaimana yang dijelaskan Simatupang et al. (1989), hal ini disebabkan sifat gypsum sebagai absorben air karena mengandung molekul hemihidrat $\left(1 / 2 \mathrm{H}_{2} \mathrm{O}\right)$, sehingga mudah mengikat air dan air yang diikat semakin banyak dengan bertambahnya proporsi gypsum.

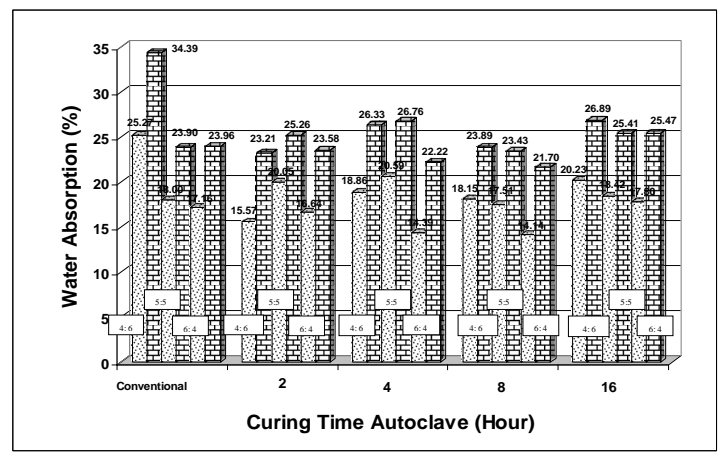

Legend :

After 2 hours immersion

: After 24 hours immerson

田

Figure 4. Histogram of board water absorption

Untuk itu diperlukan papan semen-gypsum dengan daya serap air rendah yang menunjukkan stabilitas dimensi papan semen-gypsum yang tinggi yaitu papan semen-gypsum dengan proporsi semen lebih besar dari proporsi gypsum yakni semen 60 dan gypsum 40 dengan curing autoclave 8 jam.

\section{Pengembangan Tebal dan Pengembangan Linier}

Nilai pengembangan tebal papan (Gambar 5) setelah perendaman 2 jam berkisar antara 0,21 - 0,91\%, sementara setelah perendaman 24 jam berkisar antara $0,43-1,02 \%$. Nilai tertinggi setelah perendaman 2 jam yaitu $0,91 \%$ didapat pada papan dengan proporsi semen 40 dan gypsum 60 dengan curing konvensional selama 2 minggu, sedangkan nilai terendah yaitu $0,21 \%$ didapat pada papan dengan proporsi semen 60 dan gypsum 40 dengan curing autoclave 8 jam. Setelah perendaman 24 jam nilai tertinggi yaitu $1,02 \%$ didapat pada papan yang memiliki proporsi semen 40 dan gypsum 60 dengan curing konvensional selama 2 minggu, sedangkan nilai terendah yaitu $0,43 \%$ didapat pada papan dengan proporsi semen 60 dan gypsum 40 dengan curing autoclave 8 jam.

Nilai pengembangan linier papan setelah perendaman selama 2 jam seperti terlihat pada Gambar 6 berkisar antara 0,07 - 0,23\%, dan setelah perendaman 24 jam berkisar antara 0,09 $0,31 \%$. Nilai tertinggi setelah perendaman 2 jam yaitu $0,23 \%$ didapat pada papan dengan proporsi semen 40 dan gypsum 60 dengan curing autoclave 2 jam, sedangkan nilai terendah yaitu $0,07 \%$ didapat pada papan yang memiliki proporsi semen 60 dan gypsum 40 dengan curing autoclave 8 jam. Setelah perendaman 24 jam, nilai tertinggi yaitu $0,31 \%$ didapat pada papan dengan proporsi semen 40 dan gypsum 60 dengan curing konvensional selama 2 minggu, sedangkan nilai terendah yaitu $0,09 \%$ didapat pada papan dengan proporsi semen 60 dan gypsum 40 dengan curing autoclave 16 jam.

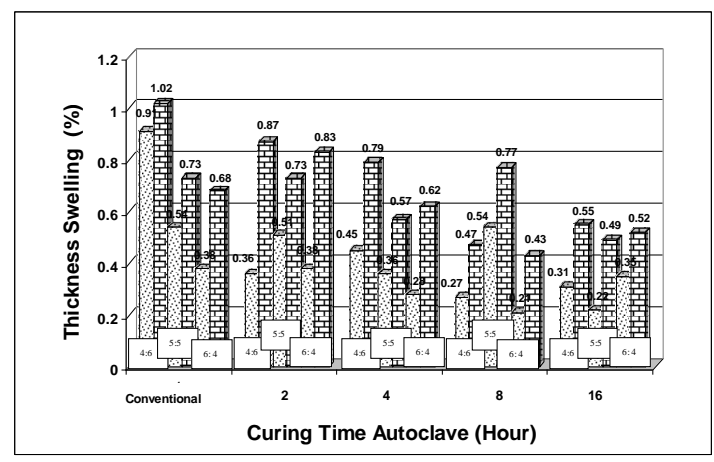

Legend: See Figure 4

Figure 5. Histogram of board thickness sweelling

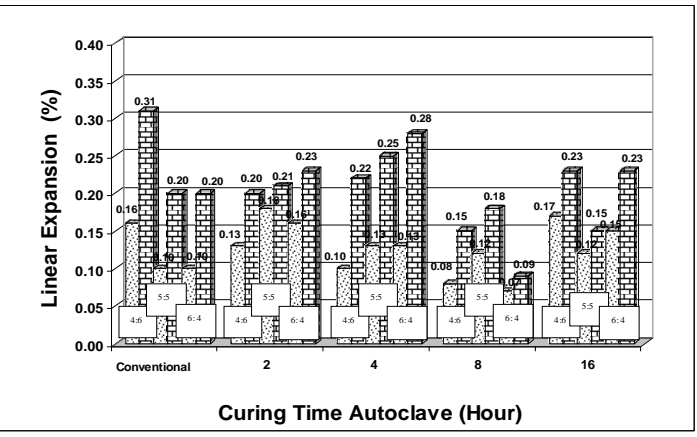

Legend : See Figure 4

Figure 6. Histogram of board linear expansion

Hasil analisis ragam menunjukkan bahwa pengembangan tebal dan linier papan semengypsum tidak dipengaruhi oleh proporsi semen- 
gypsum dan waktu curing autoclave. Hal ini berarti bahwa walaupun sifat gypsum yang absorben air dan bisa berpengaruh terhadap pengembangan tebal dan linier papan, namun secara umum proporsi semen-gypsum dan waktu curing autoclave tidak berpengaruh secara signifikan terhadap perubahan dimensi papan khususnya pengembangan tebal dan linier papan. Berdasarkan JIS A 5417-1992, yang mensyaratkan batas toleransi pengembangan tebal dan linier papan untuk tebal $12 \mathrm{~mm}$ adalah sebesar $8,3 \%$ (1 mm), maka semua jenis papan semen-gypsum yang dibuat memenuhi standar tersebut.

\section{Keteguhan Rekat (IB)}

Berdasarkan hasil pengujian seperti terlihat pada Gambar 7, keteguhan rekat (IB) papan berkisar antara $3,15-20,91 \mathrm{~kg} / \mathrm{cm}^{2}$. Nilai tertinggi yaitu $20,91 \mathrm{~kg} / \mathrm{cm}^{2}$ diperlihatkan oleh papan dengan proporsi semen 60 dan gypsum 40 dengan curing autoclave 8 jam, sedangkan nilai terendah yaitu $3,05 \mathrm{~kg} / \mathrm{cm}^{2}$ diperlihatkan oleh papan dengan proporsi semen 40 dan gypsum 60 dengan curing konvensional 2 minggu. Hasil analisis ragam menunjukkan bahwa keteguhan rekat (IB) papan semen-gypsum dipengaruhi oleh proporsi semen-gypsum dan waktu curing autoclave. Hal ini berarti bahwa dengan meningkatnya proporsi semen-gypsum dimana proporsi semen lebih besar terhadap gypsum, dan meningkatnya waktu curing autoclave dapat meningkatkan nilai keteguhan rekat pada papan yang dihasilkan. Berdasarkan JIS A5417-1992 yang mensyaratkan nilai keteguhan rekat minimal $3,10 \mathrm{~kg} / \mathrm{cm}^{2}$ maka nilai keteguhan rekat papan semen-gypsum hasil penelitian seluruhnya memenuhi standar tersebut.

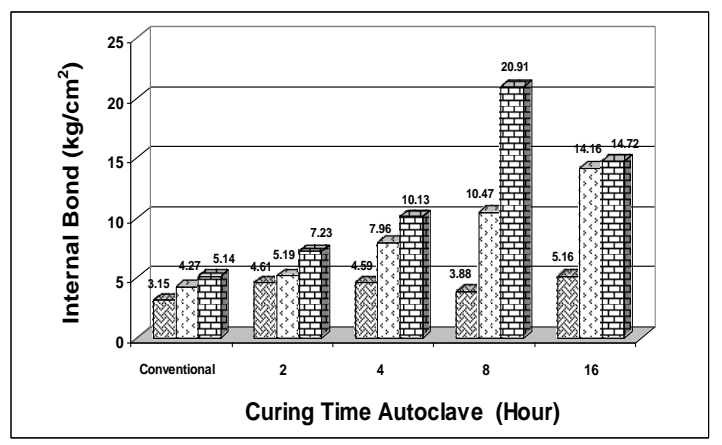

Legend : See Figure 2

Figure 7. Histogram of board internal bond
Fenomena lain yang dapat dilihat pada saat pengujian keteguhan rekat papan semengyspum adalah pola kerusakan contoh uji dimana contoh uji papan semen-gypsum mengalami kerusakan (pecah) ketika diberikan gaya tarik secara berlawanan pada arah tegak lurus permukaan papan terjadi pada lapisan tengah yang terdiri atas gypsum bercampur partikel corekenaf, sedangkan lapisan face dan back yang terdiri atas semen dan partikel core-kenaf tidak mengalami kerusakan. Fenomena tersebut membuktikan bahwa ikatan mekanis pada lapisan face dan back yang terdiri atas semen dan partikel core-kenaf lebih tinggi dibandingkan ikatan mekanis pada lapisan tengah yang terdiri atas gypsum dengan partikel core-kenaf sehingga kerusakan pada saat pengujian terjadi pada lapisan tengah. Hal ini merupakan implikasi dari terjadinya penurunan tingkat kerapatan dari bagian permukaan ke bagian tengah papan.

\section{Modulus elastisitas (MOE) dan Keteguhan Patah (MOR)}

Berdasarkan hasil pengujian seperti pada Gambar 8, modulus elastisitas (MOE) papan berkisar antara 8805 - $24429 \mathrm{~kg} / \mathrm{cm}^{2}$. Nilai tertinggi yaitu $24429 \mathrm{~kg} / \mathrm{cm}^{2}$ diperlihatkan oleh papan dengan proporsi semen 60 dan gypsum 40 dengan curing autoclave 8 jam, sedangkan nilai terendah yaitu $8805 \mathrm{~kg} / \mathrm{cm}^{2}$ diperlihatkan oleh papan yang memiliki proporsi semen 40 dan gypsum 60 dengan curing konvensional selama 2 minggu.

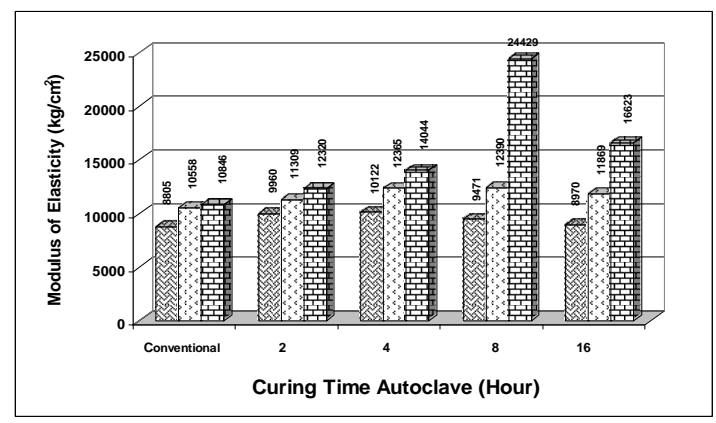

Legend : See Figure 2

Figure 8. Histogram of board MOE

Gambar 9 menunjukkan bahwa keteguhan patah (MOR) papan berkisar antara 33,19 - 84,26 $\mathrm{kg} / \mathrm{cm}^{2}$. Nilai tertinggi yaitu $84,26 \mathrm{~kg} / \mathrm{cm}^{2}$ diperlihatkan oleh papan dengan proporsi semen 60 dan gypsum 40 dengan curing autoclave 8 jam, sedangkan nilai terendah yaitu $33,19 \mathrm{~kg} / \mathrm{cm}^{2}$ 
diperlihatkan oleh papan dengan proporsi semen 40 dan gypsum 60 dengan curing konvnesional selama 2 minggu.

Hasil analisis ragam memperlihatkan bahwa modulus elastisitas dan keteguhan patah papan semen-gypsum dipengaruhi oleh proporsi semen-gypsum dan curing autoclave. Hal ini berarti bahwa dengan meningkatnya proporsi semen-gypsum dimana proporsi semen lebih besar terhadap gypsum dan meningkatnya waktu curing autoclave, dapat meningkatkan nilai modulus elastisitas dan keteguhan patah pada papan yang dihasilkan. Berdasarkan JIS A 54171992 yang mensyaratkan nilai modulus elastisitas minimal $24000 \mathrm{~kg} / \mathrm{cm}^{2}$ dan keteguhan patah minimal $63 \mathrm{~kg} / \mathrm{cm}^{2}$, maka nilai modulus elastisitas dan keteguhan patah papan semen-gypsum hasil penelitian yang memenuhi standar tersebut adalah nilai keteguhan lentur dan keteguhan patah dari papan semen-gypsum dengan proporsi semen 60 dan gypsum 40 dengan curing autoclave 8 jam.

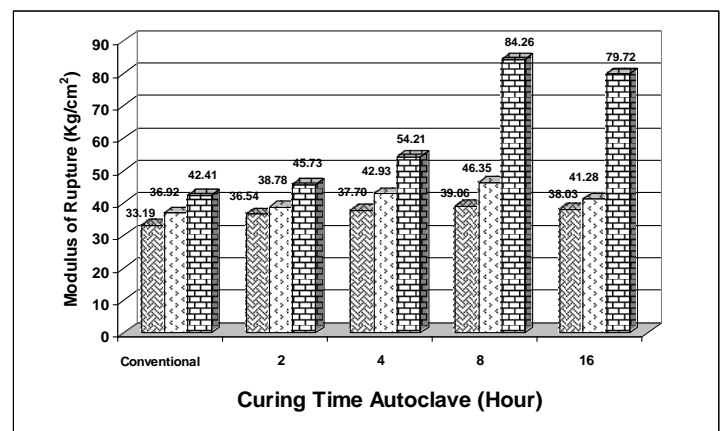

Legend : See Figure 2

Figure 9. Histogram of board MOR

\section{Kuat Pegang Sekrup}

Nilai kuat pegang sekrup papan seperti yang diperlihatkan pada Gambar 10 berkisar antara 10,50 - 20,42 kg. Nilai tertinggi yaitu 20,42 $\mathrm{kg}$ diperlihatkan oleh papan dengan proporsi semen 60 dan gypsum 40 dengan curing autoclave 8 jam, sedangkan nilai terendah yaitu $10,50 \mathrm{~kg}$ diperlihatkan oleh papan dengan proporsi semen 40 dan gypsum 60 dengan curing konvensional selama 2 minggu.

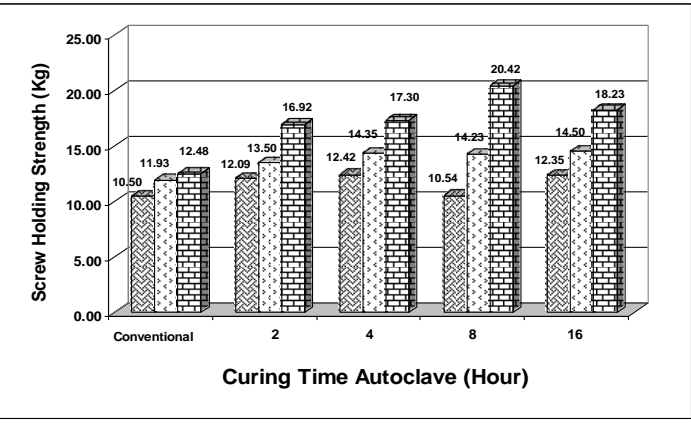

Legend : See Figure 2

Gambar 10. Histogram of board screw holding strength

Hasil analisis ragam menunjukkan bahwa nilai kuat pegang sekrup papan dipengaruhi oleh proporsi semen-gypsum dan curing autoclave. Hal ini berarti bahwa dengan meningkatnya proporsi semen-gypsum dimana proporsi semen lebih besar terhadap gypsum dan meningkatnya waktu curing autoclave, dapat meningkatkan nilai kuat pegang sekrup pada papan yang dihasilkan. Walaupun JIS A 5417-1992 tidak mensyaratkan nilai kuat pegang sekrup papan, namun papan semen-gypsum hasil penelitian yang memiliki nilai kuat pegang sekrup tertinggi adalah papan semen-gypsum dengan proporsi semen 60 dan gypsum 40 dengan curing autoclave 8 jam.

Pengujian terhadap parameter sifat mekanis papan semen-gypsum menunjukkan bahwa semua sifat mekanis papan semengypsum yang dibuat dengan curing autoclave lebih baik dimana nilai keteguhan rekat (IB), modulus elastisitas (MOE), keteguhan patah (MOR) dan kuat pegang sekrup lebih tinggi dibanding papan semen-gypsum yang dibuat dengan curing konvensional selama 2 minggu. Hal tersebut diduga disebabkan karena proses pengerasan yang dilakukan dengan autoclave (suhu $126^{\circ} \mathrm{C}$ dan tekanan $1,5 \mathrm{~kg} / \mathrm{cm}^{2}$ ) dapat menstimulir pembentukan kalsium silikat hidrat $\left(\mathrm{Ca}_{3} \mathrm{Si}_{2} \mathrm{O}_{7} \cdot 3 \mathrm{H}_{2} \mathrm{O}\right)$ sehingga proses pembentukannya menjadi lebih cepat serta meningkat pada saat reaksi pengerasan awal (setting) dan berperan penting dalam reaksi saling-kunci (interlocking reaction) dengan kalsium karbonat $\left(\mathrm{CaCO}_{3}\right)$ pada saat pengerasan lanjutan sehingga turut menunjang kekuatan papan dimana sifat mekanis papan semengypsum menjadi lebih tinggi.

\section{KESIMPULAN}


Berdasarkan hasil penelitian, dapat disimpulkan bahwa core-kenaf dapat digunakan atau sesuai sebagai bahan baku dalam pembuatan papan semen-gypsum serta proporsi semen-gypsum dan pengerasan autoclave berpengaruh nyata terhadap sifat fisis dan mekanis papan semen- gypsum dari core-kenaf. Proporsi semen 60 dan gypsum 40 dengan waktu curing autoclave 8 jam menghasilkan sifat papan semen gypsum yang memenuhi semua parameter pengujian dari standar JIS A 54171992 serta menjadikan proses pengerasan dengan autoclave lebih unggul dari curing konvensional selama 2 minggu. Melalui teknologi curing autoclave, proses pembuatan papan semen-gypsum dapat dilakukan dengan waktu yang lebih singkat dan produk papan semengypsum yang dihasilkan memiliki sifat fisis dan mekanis yang lebih baik.

\section{DAFTAR PUSTAKA}

Dempsey, JM., 1975. Fiber Crops. USA : Rose Pronting Company.

Febrianto, F., 1986. Pengaruh Nisbah Campuran Partikel Dengan Gips dan Kadar Bahan Penghambat Terhadap Sifat Fisis Mekanis Papan Gips dari Kayu Karet (Hevea brasilliensis Muell. Agr.). [Skripsi] Bogor : Fakultas Kehutanan Institut Pertanian Bogor.

Hermawan, D., 2001. Manufacture of CementBonded Particleboard Using Carbon Dioxide Curing Technology. [Ph.D.Dissertation] Kyoto Japan : Departement of Forest and Biomass Science, Graduate School of The Faculty of Agriculture Kyoto University.

[JSA] Japanese Standards Association, 1992. Cement Bonded Particle Boards. Japanese Industrial Standard (JIS) A 5417 - 1992. Japan.

Kamil, R.H.N., 1970. Prospek Pendirian Indutri Papan Wol Kayu di Indonesia. Bogor : Pengumuman No. 95. Lembaga Penelitian Hasil Hutan.

Sastrosupadi, A., 1984. Pengaruh Penggenangan Terhadap Pertumbuhan, Hasil dan Kualitas Serat serta Pulp Kayu Kenaf . [Tesis]. Bogor : Program Pascasarjana Institut Pertanian Bogor.

Simatupang, M.H., Lange H, Kasim A, Seddig N. 1989. Influence of Wood Species on The Setting of Cement and Gypsum. Di dalam : Moslemi AA, Hamel MP, editor. Proceedings Fiber and Particle Boards Bonded With Inorganic Binders; pp. 33 - 42.

Diterima: 10 Mei 2006

Rohny Setiawan Maail

Laboratorium Teknologi Hasil Hutan

Jurusan Kehutanan Fakultas Pertanian,Universitas Pattimura,Kampus Poka, Ambon

E-mail : rohny_maail@yahoo.com

Dede Hermawan dan Yusuf Sudo Hadi

Laboratorium Bio-Komposit

Departemen Hasil Hutan Fak.Kehutanan IPB, Kampus Darmaga - Bogor.

E-mail : dedemimr@yahoo.co.id

E-mail : yshadi@yahoo.com 